\title{
The Exploration of the Teaching Reform of Garden Nursery Course
}

\author{
He Xiangfeng, Zhao Hewen, Li Yuehua, Zhao Yazhou \\ College of Landscape Architecture, Beijing University of Agriculture \\ Beijing 102206
}

\begin{abstract}
Garden Nursery course is the science of studying and discussing the cultivation theory of landscape nursery stocks and their production and application technology, and it is the important basic course of landscape architecture specialty. This article discusses some problems emerging in the course of teaching it in College of Urban and Rural Development, Beijing University of Agriculture. It also puts forward corresponding teaching reform scheme, such as, letting the students know the present situation of the industry, adopting many teaching methods, reforming appraisal mechanism, arranging experimental teaching, etc., in combination with scientific research projects so as to provide new thought for the improvement of the teaching quality of the course.
\end{abstract}

Keywords-Garden Nursery; Teaching reform; Practical teaching

\section{INTRODUCTION}

Garden nurseries are the place specially cultivating nursery stocks which are the foundation of urban garden afforestation. Their ability of producing garden seedlings influences the development course and orientation of urban landscaping to some extent[1]. After the governing idea of 'beautiful China', in which the urban landscape was regarded as the important content of constructing ecological civilization and improving the people's living quality, were brought forward at the 18th National Congress of the Communist Party of China, gardening and afforestation ushers in an unprecedented development opportunity [2]. Facing the opportunity, the garden nursery industry has exposed many problems, for example, not completely rational nursery design, the employees with little expertise and scientific research consciousness, poor overall quality of nursery stocks, oldfashioned operation philosophy, low market awareness, etc [3] These problems are badly in need of the high quality professionals with systemic theoretical knowledge and practical skills of garden nurseries to join in the procession of landscaping construction.

Garden Nursery is the science of researching the kinds, habits, cultivation and application of ornamental trees and shrubs, and is one of important specialized courses of landscape architecture specialty. Through study of the course, the students can master the nursery planning and constructing rules; comprehend the main kinds, habits, ornamental characteristics and geographical distribution; know the

The author: He Xiangfeng, female, 1979, doctor, lecturer, forest tree genetics and breeding orientation. This work was supported by Research Fund for Academic Degree \& Graduate Education of Beijing University of Agriculture and Key Project of Teaching Reform of Beijing University of Agriculture in 2017 development trend and methods of the present propagation and cultivation of nursery seedlings; master the skills of garden trees selection, allocation and application; understand the relevant knowledge of operating and managing nurseries, and expertly use all of technologies and knowledge in teaching and production [4]. As one course of strong practicality, its verbose knowledge points lead to the decline of students' learning enthusiasm and the poor teaching effect. How to impart the core theoretical knowledge of the course and its latest technologies to the students in the limited class hours and let them profoundly understand the teaching contents and apply them is a subject deserving the teachers engaged in the course to ponder. The author has taught Garden Nursery course to students from many classes of College of Urban and Rural Development, Beijing University of Agriculture since 2016. To enhance teaching effect of the course, the author gives positive consideration and exploration to the teaching of the course and makes the following suggestions in accordance with personal teaching experience and the peers' researches on teaching.

\section{THE PROBLEMS EXISTING IN TEACHING}

\section{A. Insufficient initiative of the students}

At present, most students don't understand well Garden Nursery course. they one-sidedly deem that it only discusses the skills with which the professionals engaged in plant production need to be equipped and that it has little relation with their own future employment; therefore, they lack initiative in the course of learning, often don't listen in class and participate practice in a perfunctorily manner. For example, they mostly put more emphasis on the courses of planning and design and pay little attention to Garden Nursery course. In addition, the learning contents place particular stress on the theory and skills of nursery practice operation, making many students give rise to feeling of disdain and fear of difficulty and resulting in poor teaching effect.

\section{B. Single teaching form}

Because there are many knowledge points in Garden Nursery course, most teachers adopt knowledge centered education in order to transmit more information in the limited periods, and the students are in the condition of passively receiving knowledge. Their insufficient knowledge of the specialty learned plus the inflexible teaching method must 
cause lacking interest in learning, affecting teaching effect. In teaching means, most universities have widely used multimedia courseware. In contrast with the traditional blackboard teaching, the multimedia teaching has the advantage of large amount of information and being vivid and lively. However it is found that the multimedia teaching easily causes the students passively receiving, lacking thinking and weakened ability of applying knowledge, analyzing and solving problems.

\section{Unitary assessment form}

The assessment mode of Garden Nursery course is the same as most other courses, the students' total scores are composed of final examination and daily performance. The examination content mainly comes from the knowledge taught in class and the textbook. The appraisal standard, in which final closed-book examination is the main manner, causes students boning up on knowledge before the examination and quickly forgetting them after the examination. Even if they can recite the key points needed to be mastered, the students actually don't understand well. These restrict the application of related specialty knowledge in the future.

\section{Inadequate practical teaching condition}

On account of the limit of the experiment condition of the school and class hours, the students only can take part in some indoor experiments that are relatively simple, easily operated and less time - consuming, such as, seed vigor, seed germination rate experiment. Sometimes, more preparation is made by technician and course teachers in order to simplify the procedures, and the students only need operate one or two steps to finish the experiments, bringing about their incompletely mastering the knowledge and losing interest in the experimental lessons accordingly. Besides, some experiments need corresponding sites and facilities, such as, seedling pruning and grafting. Because many students of landscape architecture specialty attend the course and some students from other specialties in our school also need take related practical lessons, lots of important technologies of seedling reproduction and cultivation only can be simply demonstrated and explained, and the students have no opportunity and condition of hands-on practice.

\section{E. Less prominent key points set in the teaching contents}

Some contents of Garden Nursery course and other courses overlap, such as, land preparation and sowing, cultivation and conservation and other chapters overlap with practical courses. The students have learned related knowledge prior to Garden Nursery course, and even practically operated in some experimental lessons, but these knowledges are still regarded as the main contents to be mastered in the outline of Garden Nursery course. Arranging too many class hours in the knowledge points that have been taught must cause the students having no feeling of freshness and giving rise to learning-weariness mind.

\section{F. Needing to be improved teachers' professional skills}

Although the teachers teaching the course all have many years' teaching experience, the knowledge related to this course is not invariable. With the development of science and progress of the times, the society comes up with higher requirements to the students. Therefore the teachers need to keep up with the quick development of garden nursery industry, and to constantly absorb the latest information and master corresponding theoretical basic knowledge and practical operation skills.

\section{THE MEASURES OF TEACHING REFORM}

A series of reforms are carried out in accordance with the above mentioned problems existing in Garden Nursery course and the characteristics of the students of our school.

\section{A. To help the students to be aware of the importance of the course and foster their learning interest}

The students are emphatically told about the present status and trend of the development of the garden nursery industry in the beginning of the course in order to foster their learning interest. At the same time, the situation of some successful enterprises of garden nurseries is introduced. For example, Beijing Huangfa Nursery, as the model enterprise of national forestry standardization and seedling production base, provides large size and high quality nursery stocks to the surrounding areas of Beijing, placing positive role on the improvement of the environment quality within the areas. The enterprise gets corresponding profit while making contribution to the country and society and embodying the value of its employees. In such way, the prospect of garden nursery industry is vividly described through the actual example. So the students' learning interests are enhanced.

\section{B. To adopt many teaching methods to stimulate the students' initiative}

When the multimedia is used to the course of teaching, students are often engrossed in taking notes and the classroom atmosphere becomes dull and depressing. In order to get rid of the status, the teachers demonstrating, students autonomously asking and explaining were adopted in the theoretical teaching. The students are encouraged to 'watch and appraise' and to ask questions, discuss and solve them by the teachers and students together. Besides the classroom interaction, the discussion teaching is also the important way to enhance students' initiative. The teachers raise related questions on the basis of the course outline, and the students intensify the understanding and memory of the knowledge points through autonomous study, research, intensive discussion and other ways. Many teaching methods are adopted to motivate the students' participation awareness, learning initiative and autonomy. The field-based teaching method can be used to deepen students' understanding of relevant knowledge. For example, in the planning and construction section of the garden nursery, students can visit the nearby garden nursery, and have an intuitive understanding on the size, type, planning and design of the nursery. 


\section{To lay emphasis on the course of study and reform evaluation mechanism}

The students' performance is also involved into the evaluation system in order to better stimulate the students' learning interest. The whole course of learning is divided into many items, including attendance, class presentation, group discussion, experiment lessons, and examination. Each item occupies certain proportion in appraisal system, which can more objectively and comprehensively assess the students' performance. It also makes for promoting their profound thinking about the knowledge points while reducing the examination pressure of the theoretical lessons. The practical teaching adopts oral tests. After the reform, Garden Nursery course evaluation is relatively impersonal, and can really reflect students' learning effect. The strict assessment not only plays the role of urging the students to study hard, but also effectively improves their learning effect.

\section{To combine scientific research projects to carry out experimental teaching and enhance the manipulative ability of the students}

The experimental teaching is carried out in combination with the scientific research projects related to Garden Nursery course [5]. Before the experimental lessons begin, the teachers enlighten the students to propose the key questions to be settled and explain the experimental purpose and design principle to them so that they can independently finish the experiments. For example, the whole class can be divided into several groups to do the seed germination rate experiment, each group can carry out the experiment by different treatment, the experimental results of the whole class are finally uniformly observed, recorded and analyzed. As for the longer period experiments, the main experimental operation steps can be finished in the experimental lessons, and the students can use spare time to observe and record the subsequent phenomena. In contrast with the previous dogmatic teaching experimental operation, such teaching method greatly improves the learning initiative of the students.

\section{E. To set the key contents of the course and rationally distribute class hours}

The theory of the Garden Nursery course is based on botany, dendrology, edaphology, marketing and other subjects. Hence, some contents of the course and other courses inevitably overlap[6]. But, the class hours can be reasonably allocated through carefully checking them and properly elongated in teaching the knowledge points with which the students of the landscape architecture specialty is not in contact, for example, the planning and design of garden nursery, etc. While, the knowledge points that have been taught in other courses can be briefly introduced, and it is OK that the students are let to understand how to use them in nursery stock cultivation.

\section{F. To reinforce the construction of the teaching staff and heighten the teaching and scientific research level.}

The teachers of Garden Nursery course, on the basis of mastering teaching contents, key points, difficult points and experimental teaching, can broaden their vision through being engaged in advanced studies, visiting modern garden nurseries, drawing lessons from the related model courses of other schools, conducting cooperation and research with seedling production enterprises and through other channels to enhance their own teaching ability and academic level and lay a solid foundation for fostering the employees suitable for the contemporary garden nursery industry[6]. Besides, the rigorous scholarship of the teachers is also vital for the students listening carefully in class. The specialized teachers' teaching by their personal examples and oral instructions is conducive to foster the occupational feeling of the students so that the aim of cultivate talents is really achieved.

\section{CONCLUSION}

Putting forward of the governing concept of 'beautiful China' brings about new opportunities as well as new challenges to gardening and afforestation. Garden Nursery course is the important basic course of landscape architecture specialty. The course is essential to cultivating the high quality professionals with systemic theoretical knowledge and practical skills of garden nurseries. This article discusses some problems emerging in the course and brings up appropriate solving schemes. This requires the teachers of Garden Nursery course to adapt to the need of the times and keep in step with the front edge of the development of the garden nursery industry by constantly absorbing the latest information, being good at learning new knowledge, technology and concept and timely innovating teaching methods. They are also required to pay attention to teach by their personal examples and oral instructions, not only teaching specialized knowledge and skills to the students but also valuing the improvement of their ability of analyzing and solving questions to let them obtain all-round training. The teachers should also cultivate the occupational feeling and social responsibility of the student and see it as their mission to foster the students to become the versatile applied talents satisfying the need of the future landscaping.

\section{REFERENCES}

[1] Su Jinle. 2013. Garden Nursery (the second edition) [M]. China Agriculture Press

[2] Wang Xiaoguang. Construction of Beautiful China under the Perspective of Ecological Civilization [J]. Journal of Beijing Normal University (Social Science), 2013(2);19-25

[3] Wang Yunsheng. Thoughts and Practice of Garden Nursery Course Teaching [J]. Education and Teaching Forum, 2016(4):168-170.

[4] Sheng Lixia, Tao Jun, Shao Li, etc..Teaching Reform and Practice of Garden Nursery Course $[\mathrm{J}]$. Education and Teaching Forum, 2017(21):127-128.

[5] Wu Shasha, Zhang Linying, Peng Donghui. New Exploration of the Experimental Lesson Teaching of Garden Nursery [J]. Chinese Horticulture Abstracts, 2014(6):207-209

[6] Zhang Bianli, Lu Weina, Chai Mengying, etc. Teaching reform of garden nursery school based on application-oriented talent cultivation [J] Henan Agriculture, 2015(4):33-35 